\title{
Pewarnaan Gram Urin untuk Diagnosis Infeksi Saluran Kemih pada Anak Usia 2 Bulan hingga 2 Tahun
}

\author{
Partini Pudjiastuti Trihono, ${ }^{*}$ Riki Alkamdani, ${ }^{*}$ Aryono Hendarto, ${ }^{*}$ Dalima Ari Wahono Astrawinata** \\ ${ }^{*}$ Departemen Ilmu Kesehatan Anak, ${ }^{* *}$ Departemen Patologi Klinik Fakultas Kedokteran Universitas Indonesia/Rumah Sakit Dr. \\ Cipto Mangunkusumo, Jakarta
}

\begin{abstract}
Latar belakang. Infeksi saluran kemih (ISK) merupakan salah satu penyakit infeksi yang sering ditemukan pada anak usia 2 bulan hingga 2 tahun. Kondisi ini sulit dideteksi karena manifestasi klinis yang tidak spesifik. Kultur urin sebagai baku emas menegakkan diagnosis ISK membutuhkan waktu yang lama dan biaya yang mahal. Pewarnaan Gram urin adalah metode yang mungkin dapat digunakan untuk diagnosis dini ISK pada bayi dan anak.

Tujuan. Membandingkan metode pewarnaan Gram dan kultur urin untuk mendiagnosis ISK pada anak usia 2 bulan hingga 2 tahun. Metode. Penelitian ini merupakan uji diagnostik dengan metode potong lintang di Rumah Sakit Cipto Mangunkusumo, Jakarta, Indonesia, dari Mei 2016 -Desember 2017. Penelitian ini melibatkan 59 anak usia 2 bulan hingga 2 tahun yang dicurigai menderita ISK yang direkrut dengan metode consecutive sampling. Sampel urin diambil dengan kateterisasi uretra dan dilakukan pemeriksaan urinalisis, pewarnaan Gram, dan pemeriksaan biakan urin.

Hasil. Prevalens ISK didapatkan sebesar 38,9\%. Pewarnaan Gram urin memiliki sensitivitas 47,8\% (95\% IK 26,8-69,4\%), spesifisitas 97,2\% (95\% IK 85,5-99,9\%), nilai duga positif 91,7\% (95\% IK 60,3-98,8\%), nilai duga negatif 74,5\% (95\% IK 60,3-98,8\%), $L R(+)$ 17,2 (95\% IK 2,4-124,6), LR(-) 0,54 (95\% IK 0,36-0,8), dan akurasi sebesar 78\%.

Kesimpulan. Terdapat korelasi yang baik antara pewarnaan Gram urin dan hasil biakan urin untuk mendiagnosis ISK pada anak usia 2 bulan hingga 2 tahun. Antibiotik dapat segera diberikan setelah pewarnaan Gram menunjukkan hasil positif. Sari Pediatri $2018 ; 20(4): 230-6$
\end{abstract}

Kata kunci: infeksi saluran kemih, pewarnaan Gram, uji diagnostik

\section{A Diagnostic Study of Urine Gram Staining for Urinary Tract Infections in Young Children Aged 2 Months to 2 Years}

Partini Pudjiastuti Trihono, ${ }^{*}$ Riki Alkamdani, ${ }^{*}$ Aryono Hendarto, ${ }^{*}$ Dalima Ari Wahono Astrawinata**

Background. Urinary tract infection (UTI) is one of the most common infectious disease in young children aged 2 months to 2 years. It is often difficult to diagnose in children because of the atypical symptoms. Urine culture needs lengthy time to show results. Urine Gram staining might be used for early diagnosis of UTI in young children.

Objective. To compare the diagnostic accuracy of urine Gram staining with urine culture to diagnose UTI in children aged 2 months to 2 years.

Methods. This was a diagnostic study with cross-sectional design conducted at Cipto Mangunkusumo Hospital, Jakarta, Indonesia, from May 2016 to December 2017. This study involved 59 children recruited by consecutive sampling method. Urine sample was taken by urethral catheterization technique and sent for urinalysis, Gram staining, and urine culture.

Results. The prevalence of UTI was 38.9\%. The sensitivity of urine Gram staining was 47.8\% (95\% CI 26.8 to 69.4\%), specificity of $97.2 \%$ (95\% CI 85.5 to $99.9 \%$ ), positive predictive value of $91.7 \%$ (CI $95 \%$ from 60.3 to $98.8 \%$ ), negative predictive value of $74.5 \%$ (95\% CI 60.3 to $98.8 \%$ ), positive likelihood ratio of 17.2 (95\% CI 2.4 to 124.6 ), negative likelihood ratio of 0.54 (95\% CI 0.36 to 0.8$)$, and accuracy of $78 \%$.

Conclusion. There is a correlation between the urine Gram staining with urine culture in diagnosis of UTI in children aged 2 months- 2 years. Antibiotics should be administered immediately after urine Gram staining shows a positive result. Sari Pediatri 2018;20(4):230-6

Keywords: urinary tract infections, Gram staining, diagnostic test, young children

Studi ini telah dipresentasikan sebagai poster pada The $16^{\text {th }}$ Asia Pacific Congress of Pediatrics (APCP) 2018 di Nusa Dua, Bali, Indonesia, 25-29 Agustus 2018.

Alamat korespondensi: Partini Pudjiastuti Trihono. Departemen Ilmu Kesehatan Anak, Fakultas Kedokteran Universitas Indonesia, Rumah Sakit Cipto Mangunkusumo Jl. Diponegoro no. 71, Jakarta. E-mail: partinipt@yahoo.com 
Infeksi saluran kemih (ISK) adalah salah satu penyakit infeksi tersering pada bayi dan balita di dunia. ${ }^{1}$ Berdasarkan studi meta-analisis, prevalens ISK pada anak berusia 2 bulan hingga 2 tahun dengan gejala demam tanpa etiologi yang jelas sebanyak $7 \% .^{2}$ Sebuah penelitian kolaboratif di 7 rumah sakit di Indonesia dalam periode 5 tahun mendapatkan insidens ISK sebesar 0,1\%-1,9\%. ${ }^{3}$ Infeksi saluran kemih pada anak berusia 2 bulan hingga 2 tahun di Rumah Sakit Cipto Mangunkusumo (RSCM) didapatkan dengan angka kejadian sebesar $64 \%$.

Infeksi saluran kemih pada anak merupakan masalah morbiditas akut yang jika tidak diterapi dengan baik akan menimbulkan masalah medis di kemudian hari, berupa pembentukan jaringan parut di ginjal dan menimbulkan komplikasi pada saat dewasa, berupa hipertensi dan penyakit ginjal stadium akhir. ${ }^{5-7}$ Diagnosis ISK yang akurat sangat penting untuk memulai terapi dini yang tepat. Namun, diagnosis ISK pada anak usia muda, terutama usia 2 bulan hingga 2 tahun, seringkali tidak mudah dilakukan, karena manifestasi klinis yang tidak spesifik. Gejala ISK bawah seperti nyeri buang air kecil, polakisuria, jarang dikenali pada usia di bawah dua tahun, selain itu cara mendapatkan sampel urin yang invasif dan kelompok anak usia 2 bulan hingga 2 tahun mempunyai risiko terbesar untuk terjadinya kerusakan ginjal sebagai akibat ISK. Diagnosis yang akurat, terapi dini, dan evaluasi ISK yang adekuat diperlukan untuk mencegah pengobatan yang tidak diperlukan yang memiliki potensi bahaya yang juga besar.

Kultur urin merupakan pemeriksaan baku emas dalam mendiagnosis ISK pada anak. ${ }^{8,9}$ Namun, pemeriksaan ini membutuhkan waktu yang lama dan harga yang mahal. ${ }^{10}$ Beberapa metode skrining cepat dengan cara konvensional sudah digunakan untuk mendiagnosis ISK, di antaranya adalah pemeriksaan dipstik urin (nitrit atau leukosit esterase), uriscreen (tes katalase), dan pemeriksaan urinalisis (piuria mikroskopik). ${ }^{11-14}$ Sebuah meta-analisis menunjukkan bahwa pemeriksaan pewarnaan Gram memiliki kombinasi sensitivitas dan spesifisitas paling baik dibandingkan pemeriksaan mikroskopik dan tes dipstik. Pewarnaan Gram urin memiliki sensitivitas 93\%, spesifisitas 95\%, positive likelihood ratio 18,5, dan negative likelihood ratio of $0,7 .{ }^{15}$ Studi meta-analisis lain yang melibatkan 95.703 anak usia 0-18 tahun, menunjukkan sensitivitas pewarnaan Gram sebesar $91 \%$ dan spesifisitas $96 \% .{ }^{16}$ Pemeriksaan pewarnaan
Gram urin dapat digunakan sebagai alternatif pemeriksaan sederhana karena memiliki sensitivitas dan spesifitas yang tinggi. ${ }^{10,17}$ Saat ini belum ada studi diagnosis ISK dengan pemeriksaan pewarnaan Gram untuk anak berusia di bawah 2 tahun di Indonesia. Studi ini bertujuan untuk membandingkan akurasi pewarnaan Gram dan kultur urin sebagai baku emas diagnosis ISK pada anak berusia 2 bulan hingga 2 tahun.

\section{Metode}

Penelitian ini merupakan uji diagnostik dengan metode potong lintang yang dilakukan pada pasien rawat jalan dan rawat inap di Rumah Sakit Cipto Mangunkusumo, Jakarta, Indonesia, pada Mei 2016 hingga Desember 2017. Terdapat 71 subjek berusia 2 bulan hingga 2 tahun dengan gejala ISK yang diikut sertakan dalam penelitian. Subjek dipilih dengan metode consecutive sampling. Studi ini telah mendapatkan izin penelitian dari Komite Etik Fakultas Kedokteran Universitas Indonesia.

Subyek dicurigai menderita ISK jika ditemukan gejala-gejala, seperti demam (suhu aksila $\geq 38^{\circ} \mathrm{C}$ ) lebih dari dari 48 jam, demam dengan sumber infeksi yang belum jelas, stunting, gizi kurang, ikterus $>2$ minggu, kolestasis, sakit berat atau sepsis, atau urin berbau menyengat (foulsmelling urine). Subjek dengan kontraindikasi pemasangan kateter urin, telah mendapat antibiotik dalam 48 jam terakhir, dan ditemukan jamur pada pemeriksaan Gram atau kultur urin, dieksklusi dari penelitian ini. Seluruh orang tua dan pengasuh subjek sudah menandatangani lembar informed consents tertulis. Dilakukan pemeriksaan anamnesis, pemeriksaan fisis dan pengumpulan data demografi pasien (tanggal lahir, usia, jenis kelamin, alamat dan nomor rekam medis). Setiap subjek dilakukan pengumpulan 2 pot urin dengan miminal volume $10 \mathrm{~mL} /$ pot melalui kateter uretra. Sampel urin yang terkumpul kemudian dilakukan pemeriksaan urinalisis, kultur, dan pewarnaan Gram. Sampel urin dibawa ke laboratorium dalam waktu $<1$ jam atau disimpan dalam kontainer dengan suhu $4^{\circ} \mathrm{C}$ dan diperiksa maksimum dalam 24 jam setelah pengumpulan sampel. Kultur urin dilakukan dengan media agar darah, agar Mac Conkey, dan agar Brocalin. ${ }^{18}$ Pemeriksaan pewarnaan Gram dilakukan menggunaan urin tanpa sentrifugasi dan diperiksa dengan mikroskop cahaya. ${ }^{19}$ Kultur urin 
sebagai standar baku diagnosis ISK jika didapatkan pertumbuhan koloni bakteri $\geq 50,000 \mathrm{koloni} / \mathrm{mL}$. Pewarnaan Gram dinilai positif jika ditemukan bakteri pada pemeriksaan lapang pandang besar mikroskop.

Untuk menilai hubungan antara pewarnaan Gram dan kultur urin sebagai baku emas, dilakukan analisis terhadap sensitivitas, spesifisitas, nilai duga positif (positive predictive value/PPV), nilai duga negatif (negative predictive value/NPV), positive likelihood ratio $(\mathrm{LR}+$ ), negative likelihood ratio (LR-), dan akurasi, dengan SPSS versi 20.0.

Tabel 1. Karakteristik subjek

\begin{tabular}{|c|c|c|c|}
\hline Variabel & $\begin{array}{c}\text { Total } \\
(\mathrm{n}=59)\end{array}$ & $\begin{array}{l}\text { Kultur Positif } \\
\quad(\mathrm{n}=23)\end{array}$ & $\begin{array}{c}\text { Kultur Negatif } \\
(\mathrm{n}=36)\end{array}$ \\
\hline \multicolumn{4}{|l|}{ Jenis kelamin, $\mathrm{n}$} \\
\hline Lelaki & 34 & 17 & 17 \\
\hline Perempuan & 25 & 6 & 19 \\
\hline \multicolumn{4}{|l|}{ Kelompok usia, $\mathrm{n}$} \\
\hline \multicolumn{4}{|l|}{ Usia $2-11$ bulan } \\
\hline Lelaki & 17 & 9 & 8 \\
\hline Perempuan & 18 & 6 & 12 \\
\hline \multicolumn{4}{|l|}{ Usia $12-24$ bulan } \\
\hline Lelaki & 17 & 8 & 9 \\
\hline Perempuan & 7 & 0 & 7 \\
\hline \multicolumn{4}{|l|}{ Manifestasi klinis*, $\mathrm{n}$} \\
\hline Demam 2-14 hari & 28 & 11 & 17 \\
\hline Demam $\geq 14$ hari & 7 & 3 & 4 \\
\hline Severe wasting & 26 & 7 & 19 \\
\hline Stunting & 37 & 11 & 26 \\
\hline Kolestasis & 7 & 3 & 4 \\
\hline Sepsis & 9 & 5 & 4 \\
\hline Sakit berat & 5 & 3 & 2 \\
\hline Foul smelling urine & 3 & 2 & 1 \\
\hline Turbid urine & 2 & 2 & 0 \\
\hline Fimosis & 2 & 2 & 0 \\
\hline Orifisium uretra eksterna hiperemis & 7 & 3 & 4 \\
\hline \multicolumn{4}{|l|}{ Urinalisis, $\mathrm{n}$} \\
\hline Leukosituria $\geq 5 \mathrm{sel} / \mathrm{LPB}$ & 13 & & \\
\hline Nitrit positif & 5 & 3 & 2 \\
\hline Leukosit esterase positif & 8 & 5 & 3 \\
\hline Bakteri positif & 15 & 7 & 8 \\
\hline Semua variabel di atas positif & 2 & 2 & 0 \\
\hline \multicolumn{4}{|l|}{ Pewarnaan Gram, n } \\
\hline Ditemukan bakteri & 12 & 11 & 1 \\
\hline Tidak ditemukan bakteri & 47 & 12 & 35 \\
\hline
\end{tabular}

\section{Hasil}

Total subjek yang dilakukan pengumpulan sampel urin sebanyak 71 anak, namun hanya 63 subjek yang menyelesaikan pemeriksaan laboratorium. Empat orang subjek tidak memenuhi kriteria penelitian dan hanya 59 subjek yang dianalisis dalam penelitian ini. Karakteristik subjek tertera pada Tabel 1. Subjek penelitian terdiri atas 34 anak lelaki dan 25 anak perempuan. Prevalens ISK pada anak berusia 2 bulan

*satu subjek dapat memiliki lebih dari 1 gejala 
hingga 2 tahun pada penelitian ini sebanyak 38,9\%. Prevalens ISK lebih tinggi pada anak perempuan (17 anak) dibandingkan anak lelaki (6 anak). Dua puluh delapan subjek mengalami demam selama 2-14 hari dan hanya 7 subjek yang mengalami demam lebih dari 14 hari. Lebih dari setengah subjek (37 anak) mengalami stunting dan 26 anak mengalami severe wasting. Dari semua subjek, hanya 12 subjek yang ditemukan bakteri pada pemeriksaan urin dengan pewarnaan Gram.

Tabel 2. Pewarnaan Gram urin dibandingkan dengan kultur urin

\begin{tabular}{lcccc}
\hline & & $\begin{array}{c}\text { Kultur positif }(\geq 50.000 \\
\text { koloni } / \mathrm{mL})\end{array}$ & $\begin{array}{c}\text { Kultur negatif }(<50.000 \\
\text { koloni } / \mathrm{mL})\end{array}$ & Total \\
\hline Pewarnaan Gram & Positif & 11 & 1 & 12 \\
& Negatif & 12 & 35 & 47 \\
\hline Total & & 23 & 36 & 59 \\
\cline { 2 - 5 }
\end{tabular}

Tabel 3. Sensitivitas dan spesifisitas pewarnaan Gram dibandingkan dengan kultur urin

\begin{tabular}{lccccccc}
\hline Tes & Sensitivitas & Spesifisitas & Akurasi & PPV & NPV & LR(+) & LR(-) \\
\hline Pewarnaan Gram & $47,8 \%$ & $97,2 \%$ & $78 \%$ & $91,7 \%$ & $74,5 \%$ & 17,2 & 0,54 \\
\hline
\end{tabular}

$P P V=$ positive predictive value; $N P V=$ negative predictive value; $L R+=$ positive likelihood ratio; $L R-=$ negative likelihood ratio

Tabel 4. Distribusi subjek berdasarkan hasil isolasi bakteri yang ditemukan pada kultur urin

\begin{tabular}{lcc}
\hline & \multicolumn{2}{c}{ Kultur urin (koloni/mL) } \\
\cline { 2 - 3 } Bakteri terisolasi & $\geq 50.000(\mathrm{n}=23)$ & $<50.000(\mathrm{n}=19)$ \\
\hline Bakteri Gram negatif, $\mathrm{n}$ & 7 & 5 \\
Escherichia coli & 2 & 3 \\
Klebsiella pneumonia & 1 & 1 \\
Acinetobacter baumannii & 1 & 0 \\
Klebsiella oxytoca & 0 & 1 \\
Pseudomonas aeruginosa & 0 & 1 \\
Enterobacter sp & 0 & 1 \\
Proteus Mirabilis & 0 & 1 \\
Burkholderia cepacia & 2 & 0 \\
Klebsiella pneumonia + Escherichia coli & 1 & 0 \\
Enterococcus faecalis + Acinetobacter iwoffii & 1 & 0 \\
Proteus vulgaris + Klebsiella pneumonia & 1 & 0 \\
Proteus mirabilis + Escherichia coli & 1 & 0 \\
Proteus vulgaris + Escherichia coli & 1 & 0 \\
Klebsiella oxytoca + Proteus Mirabilis & 1 & 0 \\
Enterococcus faecalis + Escherichia coli & 0 & 1 \\
Enterococcus faecalis + Pseudomonas aeruginosa & & \\
Bakteri Gram positif, $\mathrm{n}$ & 2 & 1 \\
Enterococcus faecalis & 1 & 2 \\
Group A beta-hemolytic streptococcus & 0 & 1 \\
Staphylococcus epidermidis & 0 & 1 \\
Bacillus Sp. & 1 & 0 \\
Enterococcus faecium + Proteus mirabilis & & \\
\hline
\end{tabular}


Perbandingan tes diagnostik dengan pewarnaan Gram urin dan kultur urin sebagai baku emas untuk mendiagnosis ISK pada anak usia 2 bulan hingga 2 tahun tertera pada Tabel 2. Hanya terdapat 23 dari 59 subjek yang menunjukkan koloni bakteri $\geq 50.000$ koloni/mL pada kultur urin, yang terdiri atas 11 subjek dengan ditemukan bakteri pada pewarnaan Gram dan 12 subjek tidak ditemukan bakteri pada pewarnaan Gram.

Sensitivitas dan spesifisitas pewarnaan Gram dibandingkan dengan kultur urin tertera pada Tabel 3. Sensitivitas dan spesifisitas pewarnaan Gram dibandingkan dengan kultur urin adalah 47,8\% (95\% IK 26,8-69,4\%) dan 97,2\% (95\% IK 85,5-99,9\%). Nilai duga positif sebesar 91,7\% (95\% IK 60,3-98,8\%) dan nilai duga negatif sebesar 74,5\% (95\% IK 60,398,8\%); sedangkan LR(+) sebesar 17,2 (95\% IK 2,4124,6) dan LR(-) 0,54 (95\% IK 0,36-0,8). Akurasi pewarnaan Gram dibandingkan dengan kultur urin adalah $78 \%$.

Distribusi subjek berdasarkan bakteri yang terisolasi dalam kultur urin tertera pada Tabel 4. Escherichia Coli adalah penyebab tersering ISK yang ditemukan pada 7 subjek, diikuti dengan Klebsiella pneumonia pada 2 subjek dan kombinasi Klebsiella pneumonia + Escherichia coli pada 2 subjek. Enterococcus faecalis ditemukan pada 2 subjek dengan kultur urin positif $(\geq 50.000 \mathrm{koloni} / \mathrm{mL})$ dan 1 kultur urin negatif ( $<50.000 \mathrm{koloni} / \mathrm{mL})$.

\section{Pembahasan}

Infeksi saluran kemih (ISK) adalah infeksi yang sering terjadi pada anak. Gejala demam dipertimbangkan sebagai marka klinis keterlibatan infeksi pada parenkim ginjal (pielonefritis). Infeksi saluran kemih memiliki potensi bahaya karena dapat menimbukan kondisi akut dengan prognosis buruk. Anak berusia 2 bulan hingga 2 tahun memiliki risiko yang lebih tinggi untuk mengalami cedera ginjal, sehingga akurasi diagnosis menjadi penting untuk memulai terapi dan mencegah komplikasi ISK.

Prevalens ISK pada anak berusia 2 bulan hingga 2 tahun pada studi ini adalah 38,9\%. Hasil ini lebih tinggi dibandingkan dengan studi lain pada kelompok usia yang sama yang mendapatkan 3\%-5\%. ${ }^{5}$ Sebuah meta-analisis menunjukkan prevalens ISK pada anak di bawah 2 tahun adalah 7\% (95\% IK 5,5\%-
$8,4 \%) .^{2}$ Prevalens ISK yang tinggi pada studi ini dapat dipengaruhi oleh kondisi Rumah Sakit Cipto Mangunkusumo yang merupakan rumah sakit rujukan nasional di Indonesia.

Severe wasting merupakan manifestasi terbesar pada subjek penelitian ini (26 subjek). Studi lain menunjukkan prevalens ISK lebih tinggi pada anak dengan kondisi malnutrisi berat, seperti di Ethiopia (37\%), Afrika Selatan (34,7\%), Turki (30\%), dan India $(15,2 \%) .^{20}$

Pada studi ini didapatkan anak lelaki lebih sering mengalami ISK. Hasil serupa juga ditemukan pada studi lain yang menujukkan prevalens ISK pada anak berusia kurang dari 1 tahun lebih tinggi pada anak lelaki daripada anak perempuan. ${ }^{9}$ Studi lain menujukkan ISK pada anak yang belum disirkumsisi 5-20x lebih tinggi dibandingkan dengan anak yang sudah disirkumsisi. ${ }^{21} \mathrm{Hal}$ ini menjadi alasan mengapa 2/3 subjek berusia di bawah 1 tahun menderita ISK pada studi ini.

Sensitivitas dan spesifisitas pewarnaan Gram dibandingkan dengan kultur urin sebagai baku emas adalah $47,8 \%$ dan $92,7 \%$. Sensitivitas pada studi ini lebih rendah dibandingkan dengan studi lain yang memiliki sensitivitas $88 \% .^{22}$ Sensitivitas yang lebih tinggi juga didapatkan pada sebuah meta-analisis yakni $91 \%{ }^{16}$ dan meta-analisis lain sebesar $93 \% .{ }^{15}$ Sensitivitas yang lebih rendah pada studi ini dapat disebabkan oleh beberapa faktor seperti panas yang berlebihan selama fiksasi, rendahnya konsentrasi kristal violet, pencucian berlebihan, paparan iodin yang kurang memadai, dekolorisasi jangka panjang dan counterstaining yang berlebihan selama pewarnaan Gram. ${ }^{23}$

Spesifisitas pewarnaan Gram pada penelitian ini serupa dengan studi lain yakni $97 \%$ dan $100 \% .^{10,22}$ Spesifisitas pewarnaan Gram yang tinggi dalam mendiagnosis ISK menujukkan rendahnya hasil positif palsu. Berdasarkan hasil penelitian ini, antibiotik harus segera diberikan setelah hasil pewarnaan Gram menunjukkan hasil positif. Namun jika gejala ISK tidak khas dan pewarnaan Gram menunjukkan hasil negatif maka pemberian antibiotik harus ditunda sampai pemeriksaan kultur urin selesai.

Bakteri yang paling sering ditemukan pada kultur urin adalah Escherichia coli, Klebsiella pneumonia, dan kombinasi Klebsiella pneumonia + Escherichia coli. Bakteri Gram positif seperti Enterococcus faecalis dan Group A beta-hemolytic streptococcus juga ditemukan pada kultur urin positif. Hasil ini sesuai dengan studi 
lain yang menunjukkan ISK paling sering disebabkan oleh infeksi bakteri Gram negatif dan Escherichia coli sebanyak $88 \% .^{24}$

Penelitian ini merupakan uji diagnostik pertama untuk mendiagnosis ISK dengan menggunakan pewarnaan Gram pada anak usia 2 bulan hingga 2 tahun di Indonesia. Namun, terdapat beberapa keterbatasan pada penelitian ini. Pertama, bakteri dapat ditemukan di dalam urin jika sampel urin tidak langsung diperiksakan segera setelah pengumpulan sampel. Hal ini akan meningkatkan hasil positif palsu pada pemeriksaan Gram dan kultur urin. Kondisi ini dapat dicegah dengan menyimpan sampel urin dalam kontainer dengan suhu $4^{\circ} \mathrm{C}$ untuk menjaga kualitas sampel dan pemeriksaan harus dikerjakan maksimum dalam 24 jam sejak pengambilan sampel. Kedua, pengambilan sampel dengan kateterisasi uretra termasuk tindakan invasif dan berpotensi menimbulkan trauma. Namun, metode ini mengurangi risiko kontaminasi dan memiliki sensitivitas $95 \%$ dan spesifitas 95\% dibandingkan dengan pemeriksaan dengan aspirasi suprapubik. ${ }^{25,26}$ Teknik kateterisasi uretra membutuhkan keterampilan dan pengalaman untuk mendapatkan sampel urin yang valid, terutama pada bayi kecil, anak perempuan dan anak lelaki yang belum disirkumsisi.

\section{Kesimpulan}

Terdapat korelasi antara pewarnaan Gram dan kultur urin dalam mendiagnosis ISK pada anak usia 2 bulan hingga 2 tahun. Pemeriksaan Gram tidak dapat menggantikan kultur urin untuk mendiagnosis ISK, namun pemeriksaan Gram dapat digunakan untuk acuan pemberian terapi antibiotik yang tepat pada anak berusia 2 bulan hingga 2 tahun karena penundaan terapi dapat menyebabkan komplikasi.

\section{Daftar pustaka}

1. Hellström A, Hanson E, Hansson S, Hjälmås K, Jodal U. Association between urinary symptoms at 7 years old and previous urinary tract infection. Arch Dis Child 1991;66:232-4.

2. Shaikh N, Morone NE, Bost JE, Farrell MH. Prevalence of urinary tract infection in childhood: a meta-analysis. Pediatr Infect Dis J 2008;27:302-8.

3. Kosnandi L. Studi kolaboratif pola penyakit ginjal anak di Indonesia Dalam: Kosnadi L, Soeroso S, Suyitno H, penyunting. Naskah Lengkap Simposium Nasional Nefrologi Anak dan Peningkatan Berkala Ilmu Keseharan Anak Ke-6. Semarang: UKK Nefrologi IDAI; 1989. h. 73-90.

4. Miesien K, Tambunan T, Munasir Z. Profil klinis infeksi saluran kemih pada anak di RS dr. Cipto Mangunkusumo. Sari Pediatri 2006;7:200-6.

5. Bensman A, Dunand O, Ulinski T. Urinary tract infection Dalam: Avner ED, Harmon WE, Niaudet P, Yoshikawa N, penyunting. Pediatric Nephrology. Berlin Springer; 2009. h. 1229-310.

6. Practice parameter: the diagnosis, treatment, and evaluation of the initial urinary tract infection in febrile infants and young children. Pediatrics 1999;103:843.

7. Smellie JM, Poulton A, Prescod NP. Retrospective study of children with renal scarring associated with reflux and urinary infection. BMJ (Clinical research ed) 1994;308:1193-6.

8. Blumenthal I. Vesicoureteric reflux and urinary tract infection in children. Postgrad Med J 2006;82:31-5.

9. Zorc JJ, Kiddoo DA, Shaw KN. Diagnosis and management of pediatric urinary tract infections. Clin Microbiol Rev 2005;18:417-22.

10. Sartika IN, Suarta K, Ardhani P. Diagnostic value of urine Gram staining for urinary tract infection in children Paediatrica Indones 2009;27:302-28.

11. Zelikovic I, Adelman RD, Nancarrow PA. Urinary tract infections in children. An update. West J Med 1992;157:554-61.

12. Hoberman A, Wald ER. Urinary tract infections in young febrile children. The Pediatr Infect Dis J 1997;16:11-7.

13. Waisman Y, Zerem E, Amir L, Mimouni M. The validity of the uriscreen test for early detection of urinary tract infection in children. Pediatrics 1999;104:e41.

14. Lockhart GR, Lewander WJ, Cimini DM, Josephson SL, Linakis JG. Use of urinary Gram stain for detection of urinary tract infection in infants. Ann Emerg Med 1995;25:31-5.

15. Gorelick MH, Shaw KN. Screening tests for urinary tract infection in children: A meta-analysis. Pediatrics 1999;104:e54.

16. Williams GJ, Macaskill P, Chan SF, Turner RM, Hodson E, Craig JC. Absolute and relative accuracy of rapid urine tests for urinary tract infection in children: a meta-analysis. Lancet Infect Dis 2010;10:240-50.

17. Tilton RE, Tilton RC. Automated direct antimicrobial susceptibility testing of microscopically screened urine cultures. J Clin Microbiol 1980;11:157.

18. Dr. Cipto Mangunkusumo Hospital. Standard operationg procedur: urine culture. Jakarta: RSUPN dr. Cipto Mangunkusumo; 2012.

19. Dr. Cipto Mangunkusumo Hospital. Standard operating procedur: Gram staining. Jakarta: RSUPN dr. Cipto 
Mangunkusumo;2014.

20. Uwaezuoke SN. The prevalence of urinary tract infection in children with severe acute malnutrition: a narrative review. Pediatric Health Med Ther 2016;7:121-7.

21. Shapiro E. American Academy of Pediatrics Policy Statements on circumcision and urinary rtact infection. Rev Urol 1999;1:154-6.

22. Putri A, Rina O, Rosmayanti, Ramayanti R, Rusdidjas. Comparison of urine Gram stain and urine culture to diagnose urinary tract infection in children. Paediatr Indones 2013;10:240-50.
23. Thairu Y, Nasir I, Usman Y. Laboratory perspective of Gram staining and its significance in investigations of infectious diseases. Sub-Saharan Afr J Med 2014;1:168-74.

24. Ismaili K, Lolin K, Damry N, Alexander M, Lepage P, Hall M. Febrile urinary tract infections in 0 - to 3-month-old infants: a prospective follow-up study. J Pediatr 2011;158:91-4.

25. Leong YY, Tan KW. Bladder aspiration for diagnosis of urinary tract infection in infants and young children. J Singapore Paediatr Soc 1976;18:43-7.

26. Sorensen K, Lose G, Nathan E. Urinary tract infections and diurnal incontinence in girls. Eur J Pediatr 1988;148:146-7. 